\title{
A cellular automaton framework for within-field vineyard variance and grape production simulation
}

\author{
Subana Shanmuganathan \\ Geoinformatics Research Centre (GRC) \\ School of Computing and Mathematical Sciences, AUT \\ Auckland, New Zealand
}

\author{
Ajit Narayanan and Nick Robison \\ School of Computing and Mathematical Sciences, \\ Auckland University of Technology (AUT) \\ Auckland, New Zealand
}

\begin{abstract}
Winegrowers for generations know it all too well that grapes harvested from different areas within a vineyard will produce wines of different flavours, mainly due to within-field variance in vine vigour caused by environmental variability from various factors, such as soil properties, microclimate conditions, and rootstock. Recent research attempts on the use of state-of-the-art technologies to model/ simulate within-field variance at a vineyard scale are outlined. Consequently, the paper illustrates a cellular automaton (CA) framework being developed for simulating the within-field variance in grapevine plant vigour, phenological events and vineyard production using random or real thematic mappings of likely key factors that contribute to the observed variance. The CA approach provides an alternative software tool to conventional crop estimation methods that are dependent upon expensive yield sampling methods.
\end{abstract}

\section{Keywords; GIS, precision viticulture and grape wine}

\section{INTRODUCTION}

Viticulture and enology are among the many application areas in which modern technologies, software tools and visualisation methodologies are making a difference in achieving improvements in grape crop, both in quantity and quality, and thus in producing premium wine. The progress achieved in the last decade in producing highly refined wine labels from the world's major wine regions has been described as unprecedented (1) (2) (3) (4). It as well has led viticulturists and winemakers to further explore for more novel precision viticulture tools and methodologies to identify the high and low yield areas within-field/vineyard, the major approach of recent times has been the use of satellite imagery, aerial photo image processing and integrated analysis of geocoded data using a GIS. A brief introduction to such recent developments in the use of new technologies to better understand and manage vineyards and thereby to improve wine production is presented. Section III describes the CA approach being designed and implemented to simulate individual vine growth cycle and within-field/vineyard variability to establish the deterministic factors and their influences on crop. In section IV, results achieved thus far in implementing the approach are presented and the final section looks at future directions of this research.

\section{THE INFLUENCE OF TECHNOLOGICAL ADVANCES IN VITICULTURE}

Recent advances in georeferenced data processing and their use in vineyards have made significant changes to the ways in which vineyard operations are handled and are outlined here.

\section{A. GIS in vineyard management}

The use of geographical information systems (GIS) in viticulture research to collectively analyse geocorded data is relatively recent however, the purposes for which GIS have been investigated are quite diverse and are summarised here.

In (5) published in 1997, an observation of a paucity in the application of GIS in this area of study has been reported citing Baxevanis (1992), de Blij (1991), Dickenson (1991), ElliotFiske (1991), Rodolfi (1991), Scienza (1991), Unwin (1991) and personal communications with individuals considered to be experts in the field. The publication explored of research on the suitability of the regional aspects of wine grape production using physical characteristics of an established region in eastern California. The late 1990s research attempted to discern any unique combination of environmental parameters in vineyards that could be identified quantitatively. It was focused on developing a GIS method to describe the spatial pattern/s of vineyards using soil and physiographic parameters. The researchers were able to identify differences in 6 variables namely, slope angle, storie index ${ }^{1}$ slope, aspect, soil depth, water-holding and cation exchange capacities at the $95 \%$ confidence interval and rooting, runoff and clay content at the $85 \%$ confidence interval. Hence, the findings of the study concluded to be supportive and contributing to the literature on the significance of soil and topographic features using the then referred to as GIS methodology.

The use of GIS techniques for determining land suitability when selecting "optimal sites" for vineyards is reported in (6). The northern Italian study illustrates some early 1990s efforts made by the Italian government and prominent academic institutions of the country to integrate geospatial data with a prototype of wine viticulture cadastre for managing agricultural development planning. The publication, titled as "GIS on network" gives details on the development of a national database integrated with GIS for taxation and planning.

In recent decades, there has been intense research to unravel the Mediterranean, sometimes described as spiritual or the traditional way of grape growing and winemaking practised in

\footnotetext{
${ }^{1}$ Storie Index is a numerical expression/ value that refers to the suitability of soil for general intensive farming and it is based upon (Soil conservation Service $1974 \mathrm{p} \mathrm{43).}$ The index consists of 4 factors: soil profile, surface index, slop and specific soil limitations. It is a multiplicative index with a hierarchical suitability system ranging from 1 to 6 (i.e., most to least suitable).
} 
the "old world" wine countries over centuries. Meanwhile, the phenomenal growth observed over the last few decades in viticulture, in the "new world" wine countries Australia, New Zealand, the United States, Chile and South Africa, has introduced a new breed of competitors to the once European dominated global wine market. Hence, since the early 1990s, the old and new world wine countries have witnessed an intense demand for scientific analysis of the grapevine growing and wine industry to produce consistently good/ finer wines (7) (8) (9) and developments seen are described as unprecedented.

In an attempt to understand the traditional views, research elaborated in (10) (11) investigated the application of GIS to grapevine growth and vineyard management. The papers demonstrated the spatial and temporal variables associated with these two classes as ideally suited for GIS applications. The issues specifically looked at in the study were: scale variation, significance of location, factors that affect the production and quality of the vintage, the annual cycle of the grapevine and berry ripening and harvest, extreme events and risks (i.e., frost, pests, disease), trans-seasonal and intra-seasonal cycles, sustainability, quality and integrity of the final product, traceability and the reputation and value of the final product.

Wine grape expansion witnessed in the Cape Floristic Region of South Africa over the last decade soon after the lifting of trade sanctions in 1992 combined with the naturally fertile soil of this region led to research into modelling the land use change and its impact on the conservation planning and management of this region using spatial data (12). In that study, researchers analysed wine farmer, cellar and cooperative information gathered through a survey integrated with environmental information, such as climatic, topographic and hydro-geology and soil, using a $1 \mathrm{~km} \times 1 \mathrm{~km}$ lattice structure to identify patterns in a heterogeneous regional and local agroecosystem based on a systems approach The cellar and wine farmer location details were mapped to the lattice with presence/ absence points demonstrating the analysis of geocoded data derived from raster-polygon based GIS sources.

\section{B. Developments in Precision Viticulture}

Lately, understanding the impact of plant-soil-water dynamics at different phenological growth stages on plant physiology has been the key to achieving improved yield in within-vineyard management (13). In view of this fact an Australian report reviewed the county's technological contributions to precision management of irrigated viticulture over the past two decades. An integrated approach of mapping soil spatial properties discussed in the paper was focused on serving many purposes, such as generate irrigation management zones, evaluation of their performance and the use of near continuous soil-water profile dynamics in making irrigation scheduling, implementation and management strategies, such as regulated deficit irrigation (RDI) and partial root zone drying (PRD). Many more studies have reported on the complex and challenging issues relating to managing the dynamic relationship between site, soil, water phenological stage, vine and wine quality within and among vineyards (14). There is also research reported outside of Australia into these factors integrated with the irrigation management in grapevines which are a traditionally non-irrigated crop (15) (16) (17) (18).

\section{Satellite imagery aerial image processing in $P V$}

The availability of recent advances in remote sensing has led to a growing interest in the use of airborne multispectral and hyperspectral imagery in precision viticulture with greater flexibility especially in yield mapping integrated with soil or disease properties within a vineyard (19). The paper based on a French research reported on the most recent developments in this area of spectral characterisation of vine canopy, varietal mapping with the capability to discriminate plant species that could be used as a tool in the certification of wine productions at regional and at vineyard scales in detecting mis-planting and managing inner species variability. Subsequently, the paper investigated the use of three main approaches namely, multiple-layer perceptrons, radial basis function neural nets and support vector machines for varietal mapping. Most recent developments in this field include the use of fuzzy logic (in satellite imagery pixel analysis) and delineation of vine parcels by segmentation of high resolution (in aerial images).

Since the late 1990s, there has been significant progress in the use of precision viticulture for monitoring yield with commercially available devices and technologies (20). Yield mapping over three vintages prior to this publication in 2001, showed a number of Australian wine grape growing areas with highly varying vineyards, the variability in grape yields in single management unites being described to be as much as 8 or 10 fold. The Australian survey emphasised the need for more data within individual blocks on yield, fruit and vine indices, soil properties to optimise yield and for more refine data to find the blocks that produce high yield.

\section{CELLULAR AUTOMATION FRAMEWORK DESIGN}

The multi agent CA framework designed and being implemented in Java environment, consists of two different sets of lattices and rules for simulating grapevine growth (for Chardonnay) and yield at vine and vineyard scales. The agents are included in the framework to perform vineyard operations.

Cellular automata can be broadly described as discrete dynamical systems in which the individual cells are homogeneous (all of the same type). Through local interaction (as specified by common rules that all cells share) and a specified neighbourhood (one cell can only communicate with other cells in that neighbourhood), complex behaviour can arise over a number of generations or time-steps.

A CA is deterministic when its next state (on or off for a simply binary CA) is fully determined by its own current state and the states of neighbouring cells, and probabilistic otherwise (the next state is probabilistic). In a synchronous CA all the cells update in parallel, whereas in an asynchronic CA a cell immediately updates to the next state depending on the states of its neighbouring cells. Agents, on the other hand, are characterised by their relative autonomy (they can perform actions independently of other agents) and partial views of the global system depending on their function and decentralisation (there is no designated agent that controls all other agents). Also, and perhaps most importantly for this work, an agent can be complex (i.e. an agent can itself consist of parts specialised to perform different sub-functions). 
Merging CA with agents results in an interesting hybrid architecture where: (a) cells, in addition to communicating with other cells in their neighbourhood, also perform calculations and can receive input and send output independently of other cells; (b) cells can be grouped to perform functions specific to them (agent architectures independent of the cellular automaton architecture); and (c) cells or groups of cells can share information with each other to ensure that what is happening in one part of the system is communicated to other parts of the system. In other words, implementing CA cells as agents adds a degree of modelling power to the $\mathrm{CA}$, and implementing agents as CA cells allows agents to be located in the CA architecture in such a way that basic communication and state updating processes are provided. For modelling plant growth, a multi-agent CA framework has many advantages, including allowing a cell to represent an individual plant which in turn is complex (the plant consists of leaves, trunk, roots, etc), each of which can update its state depending on the sub-parts of neighbouring cells/plants. That is, a multi-agent CA can support many levels of interactions in a way that a simple CA cannot. Also, agents can themselves be grouped so that a population of cells can be identified to be of a specific type (e.g. chardonnay, cabernet) that have their own specific rules for interaction. Also, since cells are now relatively autonomous, they can get information and resources (such as nutrients and energy) from sources independently of any other cell or agent. Some element of competition can be introduced through agents possibly learning from their environment how to modify their interactions with other cells and how to survive on a potentially hostile environment.

There are currently no standard definitions for how to combine CA with multi-agent systems. The research design and experiments described below represent one possible hybrid approach to modelling grapevine growth and crop. Any model will ultimately be subject to the same checks as any other modelling technique: the model's ability to fit the data and/or to make predictions (using cross-validation or other train-test methods). The hybrid method adopted here is to use the CA for modelling grapevine growth both at the micro (individual plant) and macro (field of plants) levels, where agents represent the grapevine and global vineyard operations that can be broken down into components that map onto the various CA functions for updating states through local interaction. One of the purposes of agents in this hybrid architecture is to allow some degree of "non-intervention". In other words, once the hybrid architecture is set up and started for a specific number of time steps to simulate hours, days, weeks or months, the user should not have to interact with the system. Instead, the agents are responsible for collecting information from other agents and information sources, which will include actual temperature and other environmental data that the model is attempting to fit.

\section{A. Individual grapevine growth cycle and simulation}

In Viticulture, there are seven major Grapevine phenology stages/events and there are: 1) budburst, 2) leaf growth, 3) clusters of inflorescence initiation, 4) flowering, 5) berry formation, 6) development and 7) ripening. A more detailed one with 47 stages is shown in fig. 1. The chronology and triggers (changes in seasonal weather conditions) of these events are presented in fig. 2. Among the many ways, the use of growing degree days (GDD) for determining the grapevine phenology event is a more familiar one. In general GDD is calculated by adding the excess of a base temperature i.e., 10 ${ }^{\circ} \mathrm{C}$. Knowledge of phenological system characteristics developed over decades (in some wine regions even centuries) is considered as important in horticulture, especially with Vitis vinifera grapevines, the reason for this being the optimum development of quality fruit for wine production is tied to phenological occurrence and timing (21) hence used as the trigger in the initial CA simulations.

In the CA grapevine simulation discussed here, in addition to GDD, other major growth factors (soil quality, water stress and exposure to solar radiation) as well are used to calculate a variable called "available energy" (AE), the ultimate factor that determines the vine growth. The AE calculated using formula (1) and (2) is utilised for growth in five vine organs, namely trunk, bud, shoot, leaf and cluster, depending on the "stage" of the vine growth (major phenology stages 1-7). A term "priority" is used in this study to define the growth stage and this is calculated based on temperature/day length/ growing degree days (GDD/ heat units). Energy not used in the current cycle will be stored in trunk as Stored Energy (SE).
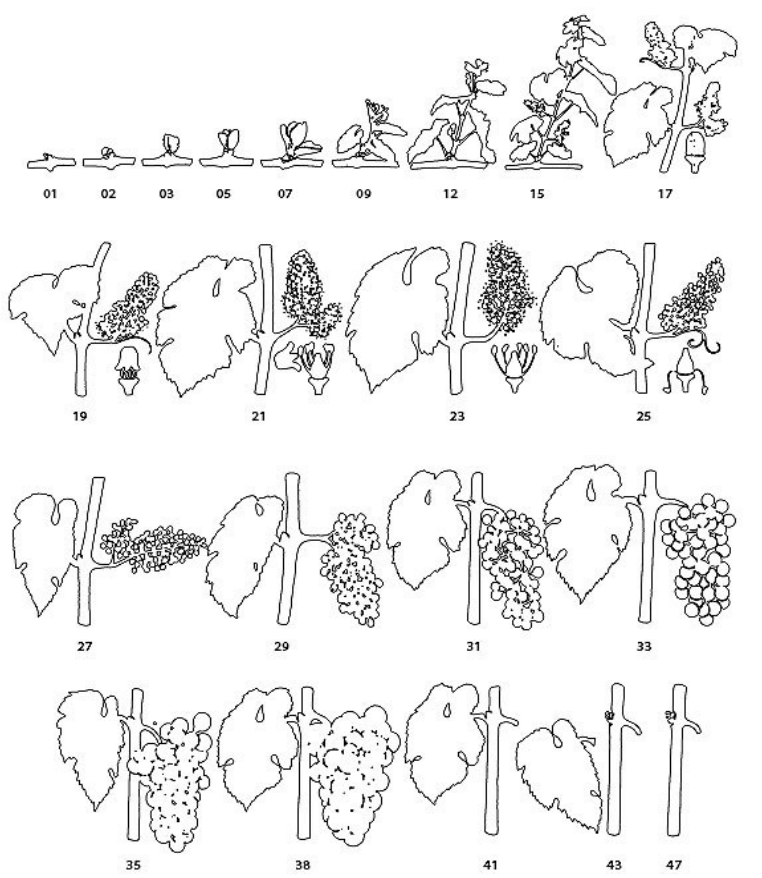

Figure 1. Phenological stages (47) of grapevine based on Coombe 1995 (22)

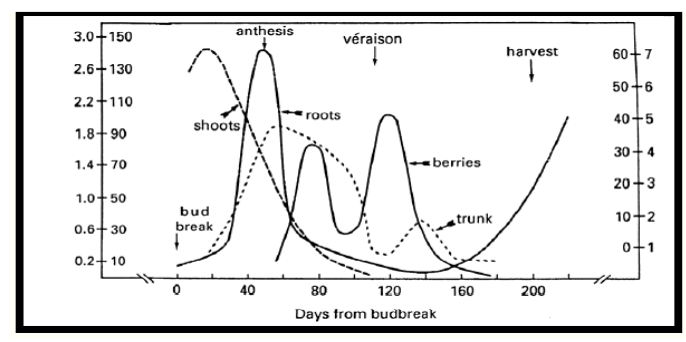

Figure 2. Chronology of grapevine phenology source: www.grapes.okstate.edu/PDFs/2009/GrapevinePhenologyandDataCollection2 009.pdf 


$$
\mathrm{AE}=((\mathrm{GDD} / \mathrm{DS}) \times \mathrm{AW} \times(\mathrm{TPV}))+\mathrm{SE}
$$

Where,

$$
\begin{array}{ll}
A E & =\text { Available energy } \\
G D D & =\text { Growing Degree Days } \\
A W & =\text { Available water }(1.0-0.0) \\
D S & =\text { Day segments } \text { (morning, } \text { noon }, \\
& \quad \text { twilight and night) } \\
T P V & =\text { Total photo synthesis value } \\
S E & =\text { Stored energy }
\end{array}
$$

$$
\mathrm{TPV}=\left(\operatorname{ALC} \times\left(\mathrm{A}^{2} \mathrm{x} \mathrm{L}\right)\right) / \mathrm{LA}^{2}
$$

Where,

$$
\begin{array}{ll}
A L C & =\text { Active leaf cover in cell } \\
C^{2} & \left.=\text { Cell area }{ }^{2} \text { (in centimetre }{ }^{2}\right) \\
L & =\text { Light }(1.0-0.0) \\
\text { Cells } & =\text { Cells in grid }
\end{array}
$$

Vine organ initiation, growth, maturity and death vary based on the type of organ and are simulated using rules in the vine CA cycle. For example, organ "leaf" grows into become a full leaf since unfolding from a "shoot". The leaf growth continues until it reaches maximum leaf blade length, stays alive for several weeks producing energy via photosynthesis and then dies off; similarly, each organ has its own growth phases and rules in the vine CA cycle (see Table 1 for bud growth rules).

\section{B. Field (vineyard) operations and simulation}

The vineyard CA is designed to allow for user input through a graphical user interface (GUI) and users can change the following parameters considered as vital in the Field simulation (fig. 4a):

Field CA lattice:

- Field width

- Field height

- Area of each cell (in cm)

Environment:

- Water quality

- Soil quality

- Light quality

Meanwhile, the following are the parameters that are designed to allow for input by users in relation to grapevine phenology:

Organs:

- Default death temperature

- Bud (B) burst threshold (in energy units calculated from (1)), B max. energy intake, B energy upkeep cost, B death temp

- Cluster (C) berry development threshold (in energy units), C. max energy intake, C. energy upkeep cost, C. Max. growth (in energy units), C. max size (in $\mathrm{cm}$ cubed)

- Shoot(S) spawn organ threshold (in energy units), S. max energy intake, S. energy upkeep cost, S. movement threshold (in energy units), S.spawn order Leaf (L) maximum growth (in energy units), L. Max. energy intake, L. energy upkeep cost, L. maximum area (in $\mathrm{cm}$ squared),
Table 1: CA rules used to simulate vine/vineyard responses

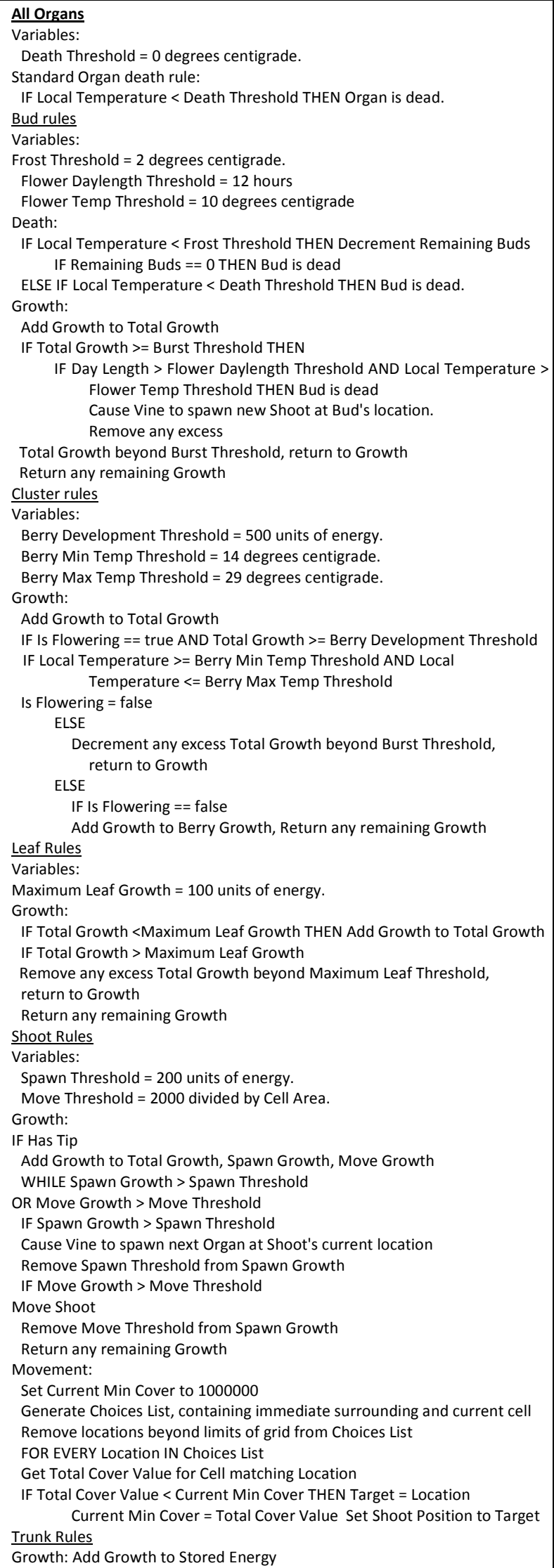


- $\quad$ Trunk (T) max. energy intake, T. energy upkeep cost

- $\quad$ Vine starting buds

\section{RESULTS}

This ongoing research is aimed at implementing a CA framework discussed in section II in Java environment for simulating perennial crop using grapevine growth and grapes harvested for individual crop and field (vineyard) scales respectively (fig. 3). The results achieved thus far demonstrate the potential of the approach for crop estimation purposes. Even with limited functions for user input through the GUI (fig. 4a), the software (sw) shows how the simulations at individual plant (vine) /meso scales, could be achieved using viticulturist expertise on the influences chosen as vital factors and their interactions at these plant/ field scales, represented as $\mathrm{CA}$ rules. $\mathrm{AE}$ is calculated using GDD, water, day segment and total photosynthesis. This is an advantage as the methods in use at this temporal scale (inter annual) use GDD alone of the local climate especially, when describing grapevine phenology (23) (24). Hence, by changing Threshold values (in this case GDD and other factors, vine phenology, vine growth and yield could be predicted under different climate and environmental change scenarios. The outcomes under an example set of these different scenarios could be viewed on the display (fig. $4 b$ ).

Currently, the database for the sw has Chardonnay wine style related information and by adding details of other styles yield predictions for them could be made under different environmental conditions as well.
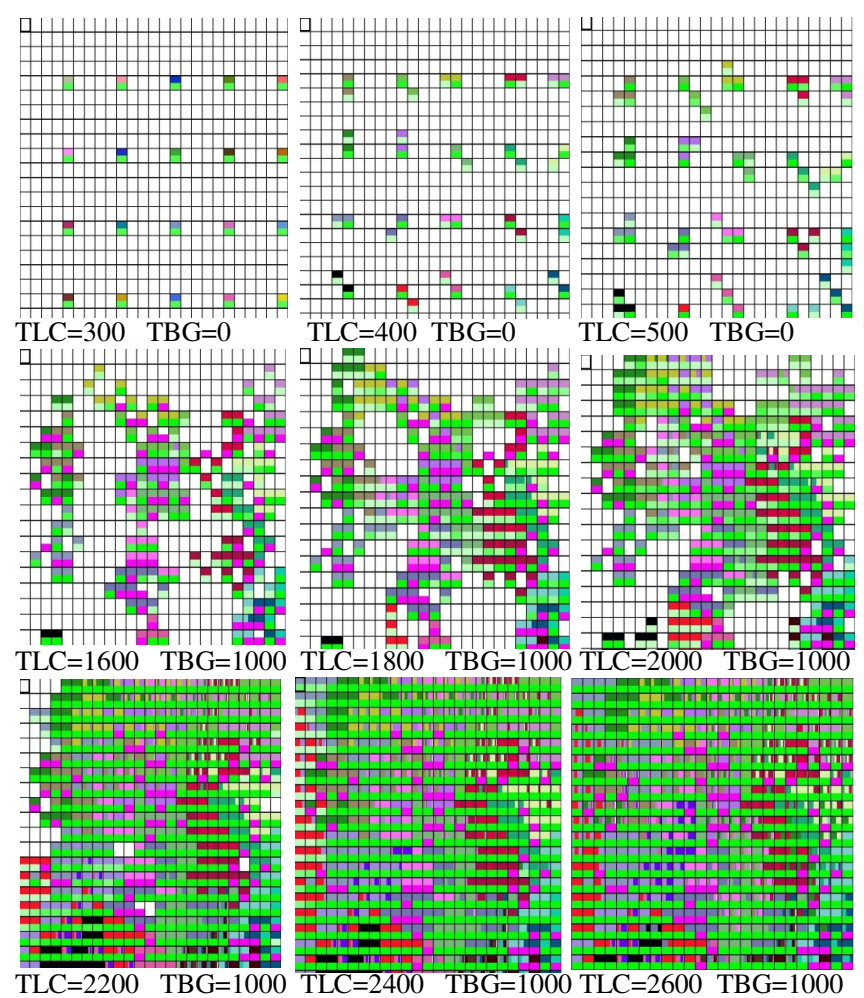
$\mathrm{TLC}=500 \quad \mathrm{TBG}=0$
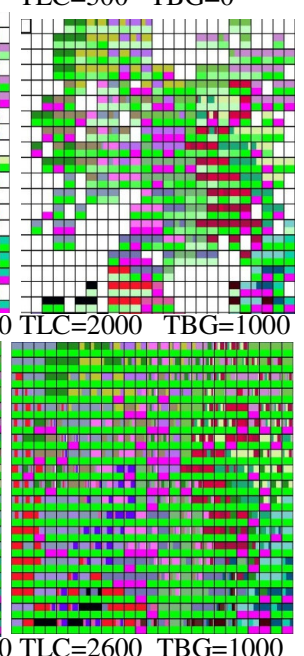

\section{CONCLUSION}

The paper described an ongoing investigation so far conducted on simulating individual plant growth and field scale interactions among vital factors using grapevine and vineyard as examples. The results of CA simulations (fig. 3) on vine and field are promising. The aerial view of leaf growth and fluorescence is shown at every $100 \mathrm{~cm} 2$ and berry growth accordingly. Such simulations will allow researchers to model effects on growth using different environmental parameter values. Future work will focus on a full implementation of the CA framework with agents to implement farming i.e., vineyard operations and an interface to change parameter values. It is anticipated that the CA simulation would enhance viticulturists ability to better predict their outcomes under different scenarios, such as pruning decisions; number of buds/ shoot to allow for full growth for that season, future climate change and at different scales, providing an alternative approach to estimating yield. The major benefit with the approach is that it provides a methodology for estimating yield without incurring any additional cost as this approach can be simulated with historic and other model prediction data. As far as the authors are aware, this is the first attempt to contribute to 'precision viticulture 'through the use of a multi-agent cellular automaton that take into account detailed information concerning both resources (energy, water) as well as important botanical features (leaves, buds, etc). In the longer term, fitting the data and making predictions about growth will need to be related to quality of wine (15). With the inclusion of a wine quality module vintage ratings as well could be predicted under different possible weather and other atmospheric conditions.

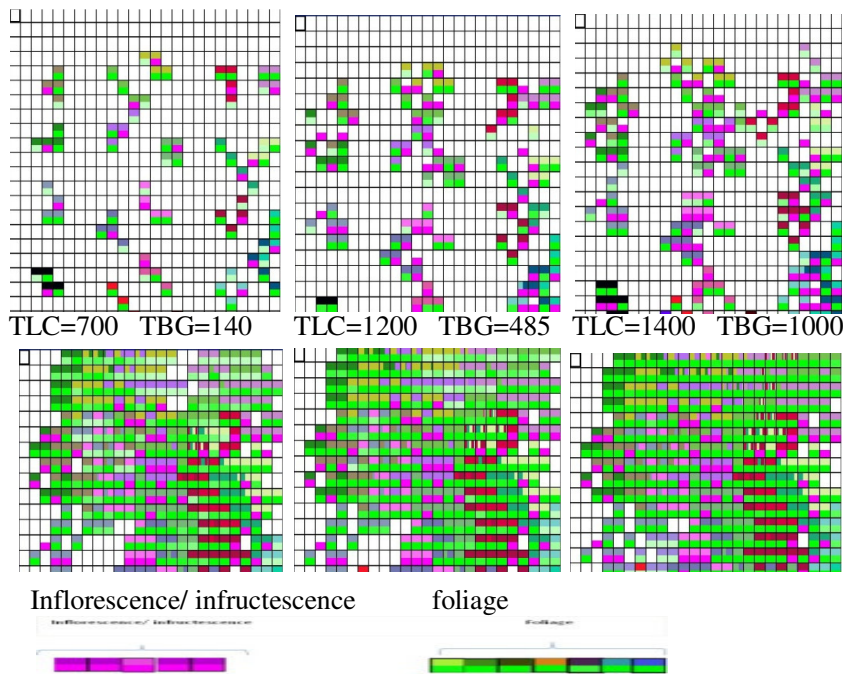

TBG (berry): Total berry growth TLC (cm2): Total leaf cover (see Fig 3)

Figure 3: CA displays showing the different phenological stages/events of grapevine growth cycle from bud break through to berry ripening. The GUI is set to run from bud break to harvest with 20 grapevines. The threshold values set for different phenological events are shown in (Fig. 4 a) for grapevine and vineyard growth stages as shown in figs 1 and 2 . 


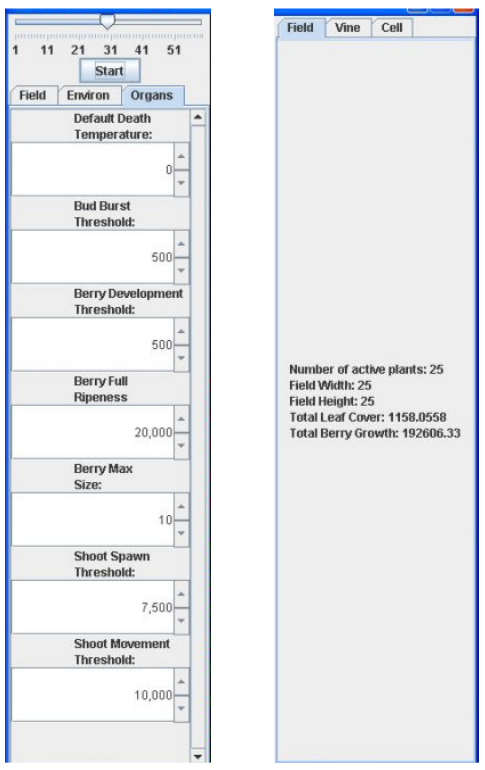

Figure 4: Screen displays for a) user input for different parameters (left) and b) Plant (CA cell)/ vineyard growth (left) calculated and displayed based on CA rules in Table 1.

Furthermore, with the use of real data on soil quality Chemical test data) and vegetative growth vigour (calculated using satellite imagery) in the simulation, yield prediction accuracy could be further enhanced. In summary, this paper presents a first demonstration of interim results gained through a novel modelling approach using cellular automata for understanding grape vine phenology, growth at micro/meso scales and environmental effects. The application of artificial life techniques, such as cellular automata, provide a natureinspired approach for precision viticulture.

\section{ACKNOWLEDGMENT}

The authors wish to thank Michel Brakavich, Kumeu River Wines. Prof Philip Sallis and Peter Sumich of AUT are acknowledged for their continuous support

\section{REFERENCES}

[1] Jones, G V and Davis, R. USING A SYNOPTIC CLIMATOLOGICAL APPROACH TO UNDERSTAND CLIMATE-VITICULTURE RELATIONSHIPS. s.l. : Int. J. Climatol. 20: 813-837 (2000), 2000.

[2] Matese, A, et al. A wireless sensor network for precision viticulture: The NAV system. Computers and Electronics in Agriculture 69 (2009) $51-58,2009$.

[3] Best, S, León, L and Claret, M. Use of Precision Viticulture Tools to Optimize the Harvest of High Quality Grapes. in proceedings of Information and Technology for Sustainable Fruit and Vegetable Production FRUTIC 05, 12-16 September 2005, Montpellier France, 2005. www.symposcience.org/exl-doc/colloque/ART-00001647.pdf.

[4] Lamb, D. Introduction, Rationale for the workshop: CRCV Project 1.1.1 Precision Viticulture in Vineyard monitoring and management beyond 2000. Australia : CRC for Viticulture, PO Box 154, Glen Osmond, SA, 5064 and National Wine \& Grape Industry Centre, Charles Sturt $\begin{array}{llll}\text { University, } \quad \text { WaggaWagga, 2678, NSW, } & 1999 .\end{array}$ http://www.crcv.com.au/research/programs/one/finalreport.pdf.

[5] Watkins, R.L., V.F. Meyer, and Assoc,. Vineyard site suitability in Eastern California. Vols. GeoJournal, 1997. 43(3): p.229-239.
[6] Galetto, R, et al. GIS ON NETWORK: A PROTOTYPE OF WINE VITICULTURE CADASTRE TO MANAGE AGRICULTURAL DEVELOPMENT PLANNING, D.O.C.(ORIGIN CONTROLLED DENOMINATION CERTIFICATE) PRODUCTION AND DISTRIBUTED CITIZEN SERVICES. Firenze, Italy: 13 ESRI European Conference 1998., 1998. http://proceedings.esri.com/library/userconf/europroc98/proc/idp118.html.

[7] White, R E. Soils for Fine Wines. Oxford : s.n., 2004.

[8] Campbell, G and Guibert, N. The impact of globalisation on the wine industry. United Kingdom 2006. Vol. 332 pp107 146.

[9] Labys, W C and Cohen, B C. Trends versus cycles in global wine export shares. 2006. Vol. 2006 50(4):p.527-537.

[10] Smith, L and Firns, P. Applied Research into the Integration of Spatial Information Systems with Viticultural Research \& Vineyard Management Systems. University of Otago, New Zealand: 10th Colloquium of the Spatial Information Research Centre, 1998.

[11] Smith, L and Whigham, P. Spatial Aspects of Vineyard Management and Wine Grape Production Information Research Centre. University of Otago, Dunedin, New Zealand : 11th Annual Colloquium of the Spatial Information Research Centre, 1999.

[12] Fairbanks, D H K, Hughes, C J and Turpie, J K. Potential impact of viticulture expansion on habitat types in the Cape Floristic Region, South Africa. 2004.

[13] Buss, P, et al. Precision management in viticulture - an overview of an Australian integrated approach. in proceedings of seminar on Integrated soil and water management for orchard development FOOD AND AGRICULTURE ORGANIZATION OF THE UNITED NATIONS pp51-57, 2005. ftp://ftp.fao.org/docrep/fao/009/a0007e/a0007e02.pdf.

[14] Fuentes, S. Precision irrigation for grapevines (Vitis vinifera L.) under RDI and PRD, PhD thesis. University of Western Sydney, Australia, 2005. NUWS20060713.093402. http://library.uws.edu.au/adt-NUWS/public/adt-

[15] Cifre, J, et al. Physiological tools for irrigation scheduling in grapevine (Vitis vinifera L.) An open gate to improve water-use efficiency? Agriculture, Ecosystems and Environment 106 (2005) 159-170, 2005. doi:10.1016/j.agee.2004.10.005.

[16] Ben-Asher, J, et al. Irrigation of grapevines with saline water: II. Mathematical simulation of vine growth and yield. Agricultural Water Management Vol. 83, Issues 1-2, 16 May 2006, Pages 22-29, 2006.

[17] Patakas, A, Noitsakis, B and Chouzouri, A. Optimization of irrigation water use in grapevines using the relationship between transpiration and plant water status. s.1. : Ecosystems \& Environment, 2005. 106(2-3, 2 April 2005): p. 253-259, 2005. doi:10.1016/j.agee.2004.10.013.

[18] Guix-Hébrard, N, et al. Influence of watertable depths on the variation of grapevine water status at the landscape scale. European Journal of Agronomy, 2007 27(2-4, October 2007): p. 187-196, 2007.

[19] Ferreiro-Arm'an, M, et al. Hyperspectral Image Analysis for Precision Viticulture. Author manuscript, published in "International Conference on Image Analysis and Recognition, Portugal (2006)", 2006. http://hal.archives-ouvertes.fr/docs/00/39/95/67/PDF/LNCS-ICIAR2006-Personal.pdf.

[20] Bramley, R G V. Vineyard sampling for more precise, targeted management. First Australian Geospatial Information and Agriculture Conference, Sydney, Australia, 17-19 July 20012001 pp. 417-427, 2001. www.cabdirect.org/abstracts/20023169277.html?freeview=true.

[21] Jones, G V, et al. Changes in European wine grape phenology and relationships with climate. in Proceedings of the Groupe d'Etude des Systèmes de Conduite de la vigne (GESCO 2005), Gesellschaft zur Forderung derForschungsanstalt, Geisenheim, Germany, 23-27 August, 2005.

[22] Coombe, B G. Adoption of a system for identifying grapevine vine growth stages. . Aust. J. Grape Wine Res. 1:100-110., 1995.

[23] van Leeuwen, Cornelis, et al. Influence of Climate, Soil, and Cultivar on Terroir. Am. J. Enol. Vitic. 2004 55:207-217, 2004.

[24] Ashenfelter, O, Ashmore, D and Lalonde, R. Bordeaux Wine Vintage Quality and the Weather. Chance vol 8 No. 41995: 7-14., 1995. 